\title{
Phase II trial of prophylactic hyperthermic intraperitoneal chemotherapy in patients with locally advanced gastric cancer after curative surgery
}

Biao Fan, Zhaode Bu, Ji Zhang, Xianglong Zong, Xin Ji, Tao Fu, Ziyu Jia, Yinan Zhang and Xiaojiang Wu*(D)

\begin{abstract}
Background: HIPEC is an emerging procedure to treat peritoneal metastasis of gastric cancer. Data about HIPEC in locally advanced gastric cancer is scarce. The purpose of this trial is to evaluate the safety and toxicity of prophylactic HIPEC with cisplatin for patients with locally advanced gastric cancer.

Methods: From March 2015 to November 2016, a prospective, randomized phase II trial was conducted. After radical gastrectomy, patients in the experimental group underwent HIPEC with cisplatin followed by adjuvant chemotherapy with SOX regime. Patients in the other group were treated with SOX regime alone. Postoperative complications and patient survival were compared.

Results: In total, 50 patients were eligible for analyses. No significant difference was found in the incidence of postoperative complications including anastomotic/intestinal leakage, liver dysfunction, bone marrow suppression, wound infection and ileus $(P>0.05)$. Mean duration of hospitalization after radical gastrectomy was 11.7 days. 12.2 days in experimental group and 10.8 days in control group respectively $(P=0.255)$. The percentage of patients with elevated tumor markers was $12.1 \%$ in experimental group, which was significantly lower than $41.2 \%$ in control group $(P=0.02)$. 3-year RFS of patients who treated with or without prophylactic HIPEC were 84.8 and $88.2 \%$ respectively $(P=0.986)$. In the multivariate analysis, pathological T stage was the only independent risk factor for the RFS of patients $(P=0.012, \mathrm{HR}=15.071)$.

Conclusion: Additional intraoperative HIPEC with cisplatin did not increase postoperative complications for locally advanced gastric cancer after curative surgery. Prophylactic HIPEC with cisplatin was safe and tolerable, while it did not reduce the risk of peritoneal recurrence in this trial, supporting further studies to validate the efficacy of it.
\end{abstract}

Trial registration: Chinese Clinical Trial Registry, ChiCTR2000038331. Registered 18 September 2020 Retrospectively registered, http://www.chictr.org.cn/showproj.aspx?.proj=59692.

Keywords: Locally advanced gastric cancer, HIPEC, Cisplatin, Safety, Clinical efficacy

\footnotetext{
*Correspondence: drwuxiaojiang@163.com

Key Laboratory of Carcinogenesis and Translational Research (Ministry of Education), Gastrointestinal Cancer center, Peking University Cancer Hospital and Institute, Fu-Cheng Road 52\#, Hai-Dian District, Beijing 100142, China
}

(C) The Author(s). 2021 Open Access This article is licensed under a Creative Commons Attribution 4.0 International License, which permits use, sharing, adaptation, distribution and reproduction in any medium or format, as long as you give appropriate credit to the original author(s) and the source, provide a link to the Creative Commons licence, and indicate if changes were made. The images or other third party material in this article are included in the article's Creative Commons licence, unless indicated otherwise in a credit line to the material. If material is not included in the article's Creative Commons licence and your intended use is not permitted by statutory regulation or exceeds the permitted use, you will need to obtain permission directly from the copyright holder. To view a copy of this licence, visit http://creativecommons.org/licenses/by/4.0/ The Creative Commons Public Domain Dedication waiver (http://creativecommons.org/publicdomain/zero/1.0/) applies to the data made available in this article, unless otherwise stated in a credit line to the data. 


\section{Background}

Gastric cancers is one of the most common cancer in the world, especially in Asian countries such as China, Japan and Korea [1, 2]. Peritoneal recurrence is a common pattern of gastric cancer recurrence, and it often indicates poor prognosis [3-5]. When compared with lymphatic and hematogenous metastasis, peritoneal metastasis is considered as a local disease that could be treated by HIPEC. HIPEC is an effective procedure for peritoneal metastasis of multiple cancers, including ovarian cancer and appendix mucinous adenocarcinoma, by which a high concentration of chemotherapeutic drug can directly act on peritoneal cancer cells and nodules [6-9]. There is also some clinical evidence supporting the efficacy of HIPEC for peritoneal metastasis of gastric cancer [10-13].

For the locally advanced gastric cancer, without noncurative factors, the most widely accepted therapies are neoadjuvant chemotherapy and radical gastrectomy plus D2 lymphadenectomy followed by adjuvant chemotherapy. Based on the seed and soil theory, peritoneal metastasis is defined as the implantation and progression of cancer cells seeded on peritoneum [14-16]. Studies have demonstrated that peritoneal micro-metastasis was detected in 5-20.5\% of patients with locally advanced gastric cancer [17-19]. Serosal invasion in gastric cancer was positively correlated with positive peritoneal wash cytology, which was thought to be the early stage of macroscopic peritoneal metastasis [20, 21]. After radical surgery, $43-45.9 \%$ of gastric cancer patients will suffer from peritoneal recurrence [22, 23].

The use of HIPEC is considered as a potential prophylactic approach to avoid peritoneal recurrence of cancer. Nevertheless, data about prophylactic HIPEC in gastric cancer is scarce, and it is difficult to outline its role against peritoneal recurrence. In this study, we evaluated the post-operational complications and outcomes of gastric cancer patients who underwent radical gastrectomy followed by HIPEC with cisplatin, focusing our analysis on the safety and tolerability of the experimental treatment, which could influence patient survival.

\section{Methods}

\section{Study design and patients}

This was a prospective, randomized, single center study conducted from March 2015 to November 2016. Patients with locally advanced gastric cancer (cT3-4 N0-3 M0) treated with radical gastrectomy at the Gastrointestinal Cancer Center of Peking University Cancer Hospital \& Institute were enrolled. The clinical stage of patients was based on radiology results. There was no distant metastasis such as liver metastasis, lung metastasis and peritoneal metastasis in all patients. Diagnostic laparoscopy revealed that they all had negative cytology.
According to the preliminary data, the peritoneal recurrence rate is $35 \%$ within 1 year after radical surgery in locally advanced gastric cancer patients treated without HIPEC (the control group proportion: 0.35 ), while that is $10 \%$ in patients treated with HIPEC (the experimental group proportion: 0.10 ). In this trial, the allocation ratio of patients in the experimental group and the control group is 2:1. The experimental group proportion is assumed to be 0.32 under the null hypothesis and 0.10 under the alternative hypothesis. The test statistic used is the two-sided Z test (unpooled). Using PASS 11, the required sample size should be 116 patients (77 patients in the experimental group and 39 patients in the control group), with a two-sided alpha level of $5 \%$ and a power of $80 \%$. However, the trial was prematurely terminated after 50 patients enrolled, owing to the end of cooperation with the company that provided the HIPEC system (BR-TRG-II). This study was approved by the Ethics committee of Peking University Cancer Hospital. Written informed consent was obtained from all patients. The study adhered to CONSORT guidelines and it was registered at the Chinese Clinical Trial Registry (ChiCTR2000038331).

\section{Randomization and procedure of HIPEC}

After radical gastrectomy, patients were randomly divided into two groups (a two-to-one ratio), namely, the experimental group (included patients who were treated with HIPEC followed by adjuvant chemotherapy with SOX regime) and the control group (included patients who underwent adjuvant chemotherapy with SOX regime alone). Randomization was performed via a computer generated sequence. In the experimental group, HIPEC was performed under general anesthesia after radical gastrectomy. Two outlet pipes and one inlet pipe were installed. Cisplatin $(50 \mathrm{mg} / \mathrm{L})$ was diluted in heated $0.9 \%$ sodium chloride and then circulated for $30 \mathrm{~min}$. Perfusion rate was $400-500 \mathrm{ml} / \mathrm{min}$. The circulation temperature was $42.5^{\circ} \mathrm{C}-43.0^{\circ} \mathrm{C}$. HIPEC perfusion and circulation was performed with BR-TRG-II (Bright Medical Technology Co.,Ltd., Guangzhou, China). After the HIPEC was finished, at least $90 \%$ of perfusion fluid was removed.

\section{Procedure of adjuvant chemotherapy}

Pathologically, all patients with locally advanced gastric cancer received postoperative adjuvant chemotherapy (a 3 week cycle SOX regime). S-1, 40-60 mg (40 mg when BSA $<1.25 \mathrm{~m}^{2}, 60 \mathrm{mg}$ when BSA $\left.>1.5 \mathrm{~m}^{2}\right)$, twice per day, Day 1-14; Oxaliplatin $\left(130 \mathrm{mg} / \mathrm{m}^{2}\right)$ was given intravenously at the first day of each cycle. Toxicity of the regime was graded based on the Common Terminology Criteria for Adverse Events version 4.0. 
Clinical parameters and postoperative follow-up

Clinico-pathological parameters including tumor size, tumor differentiation, TNM stage, hospitalization day after surgery, drainage tube removal time and postoperative complications such as anastomotic leakage were prospectively recorded and analyzed. The primary endpoint was 3-year RFS. The secondary endpoint was the incidence of postoperative complications (based on Clavien-Dindo classification).

\section{Statistical analysis}

Incidence of postoperative complications and patient outcome were compared. All statistical analyses were performed by using SPSS Statistics software version 17.0. Clinico-pathological characteristics and incidence of postoperative complications in both groups were compared via a two-tailed independent-sample t-test or a nonparametric tests. The Kaplan-Meier analysis was performed to estimate survival rates. Multivariate analysis was used for survival analysis. A two-sided $P<0.05$ was taken as significant.

\section{Results}

\section{Baseline data}

In total, 50 patients (median age, 61 years old; range, 46-86 years old) from March 2015 to November 2016 were enrolled. Median follow-up was 37 months. Of these patients, 33 patients were performed HIPEC with cisplatin, the others underwent adjuvant SOX regime alone. Patients in this study were well balanced and comparable regarding baseline clinic-pathological parameters $(P>0.05$; Table 1$)$.

\section{Tumor markers changing tendency and adverse events} The percentage of patients with elevated tumor markers was $12.1 \%$ in experimental group, which was significantly lower than in control group $(41.2 \% ; P=0.02)$. There was no statistically significant difference between the occurrence rates of postoperative complications $(P>$ 0.05; Table 2). Anastomotic or intestinal leakage occurred in 5 patients, 1 in control group (5.9\%) and 4 in experimental group $(12.1 \%)(P=0.49)$. Three grade II liver dysfunction developed in control group, while 8 in experimental group $(P=0.773)$. Four patients showed grade II bone marrow suppression, 2 in each group. Neither wound infection nor ileus occurred in either groups. Mean duration of hospitalization after radical gastrectomy was 11.7 days. 12.2 days in experimental group and 10.8 days in control group respectively $(P=0.255)$. Mean drainage tube removal time after surgery was 9.7 days. 10.2 days in experimental group and 8.6 days in control group respectively $(P=0.159)$.

\section{Survival and recurrence}

The follow-up time ranged from 36 to 48 months (median: 37 months). 3-year overall survival rate of the whole cohort was $92,87.9 \%$ in experimental group and $100 \%$ in control group respectively $(P=0.142$; Fig. 1 a). The 3-year RFS rates of patients who underwent HIPEC or not were 84.8 and $88.2 \%$ respectively $(P=0.980$; Fig. 1b). Prognostic factors were pathological $\mathrm{T}$ stage, $\mathrm{N}$

Table 1 Clinico-pathological parameters of fifty locally advanced gastric cancer patients treated with/without prophylactic HIPEC

\begin{tabular}{lll}
\hline Age & Control group $(\boldsymbol{n}=\mathbf{1 7})$ & Experimental group $(\boldsymbol{n}=\mathbf{3 3})$ \\
Sex, M/F & $60(50-86)$ & (46-78) \\
KPS, 90/100 & $14 / 3$ & $18 / 15$ \\
BMI & $9 / 8$ & $23(16-34.5)$ \\
Disease history, Yes/No & $21(15-32)$ & $13 / 20$ \\
Location, U/M/L & $11 / 6$ & $14 / 4 / 15$ \\
Size, $<5$ cm/ $\geq 5$ cm & $5 / 3 / 9$ & $16 / 17$ \\
Gastrectomy, Sub. /Tot. & $13 / 4$ & $15 / 18$ \\
Histological diagnosis, Well/intermediately versus poorly/undifferentiated & $10 / 7$ & $11 / 12$ \\
Lauren classification, Intestinal/diffuse/mixed & $10 / 7$ & $13 / 6 / 12$ \\
Lymphovascular invasion, Yes/No & $6 / 6 / 4$ & $18 / 15$ \\
Neurovascular invasion, Yes/No & $6 / 11$ & $15 / 18$ \\
T stage, $1 \sim 3 / 4$ & $9 / 8$ & $22 / 11$ \\
N stage, 0/1 3 & $12 / 5$ & $10 / 23$ \\
Ki67 IHC & $10 / 7$ & $60 \%(10-90 \%)$ \\
MSS/MSI & $75 \%(50-99 \%)$ & $26 / 2$
\end{tabular}

KPS karnofsky performance score; BMI body mass index; MSS/MSI micro-satellite stable/instable 
Table 2 Postoperative complications in patients treated with/without prophylactic HIPEC

\begin{tabular}{llll}
\hline & Control group $(\boldsymbol{n}=\mathbf{1 7})$ & Experimental group $(\boldsymbol{n}=\mathbf{3 3})$ & $\boldsymbol{P}$ value \\
\hline Alb $(<35 \mathrm{~g} / \mathrm{L} / \geq 35 \mathrm{~g} / \mathrm{L})$ & $15 / 2$ & $25 / 8$ & 0.069 \\
Change of tumor markers, Decrease/stable/increase & $1 / 9 / 7$ & $6 / 23 / 4$ & 0.020 \\
Median hospitalization day after surgery & $10(7-22)$ & $11(8-24)$ & 0.255 \\
Median drainage tube removal time after surgery & $8(6-17)$ & $4(5-24)$ & 0.159 \\
Anastomotic leakage/Intestinal leakage, Yes/No & $1 / 16$ & $4 / 29$ & 0.490 \\
Wound infection/Poor wound healing, Yes/No & $0 / 17$ & $0 / 33$ & 1.000 \\
lleus, Yes/No & $0 / 17$ & $0 / 33$ & 1.000 \\
Leukopenia, None/grade I/II & $13 / 2 / 2$ & $25 / 6 / 2$ & 0.956 \\
Neutropenia, None/grade I/II & $13 / 2 / 2$ & $28 / 3 / 2$ & 0.453 \\
Liver dysfunction, None/grade I/II & $4 / 10 / 3$ & $10 / 15 / 8$ & 0.773 \\
\hline
\end{tabular}

Alb Albumin

stage, pTNM stage and tumor differentiation by univariate analysis $(P<0.05$; Fig. 2a-d). Multivariate analysis of RFS showed that only pathological T stage (RR $15.071, P=0.012)$ was significantly associated with prognosis (Table 3 ).

\section{Discussion}

Peritoneal recurrence often occurs in gastric cancer patients after radical gastrectomy. Prognosis of the patient with peritoneal recurrence is very poor, median survival time of which is less than 7 months [24]. During the progression of locally advanced gastric cancer, cancer cells are likely to seed on the peritoneum that results in peritoneal dissemination after they invade through serosal layer of gastric wall [25]. Therefore, the deeper the depth of gastric cancer invasion, the more likely to occur peritoneal metastasis or recurrence. HIPEC is an effective method can be used to treat peritoneal metastasis of some cancers. Whether HIPEC can be used to prevent or delay peritoneal recurrence of locally advanced gastric cancer, especially when cancer cells have infiltrated into serous layer of gastric wall, is still obscure. This study was a randomized controlled trial to clarify the safety and tolerability of HIPEC after curative resection for locally advanced gastric cancer. Results showed that administration of HIPEC with cisplatin was safe and well tolerated with low complications and short duration of hospitalization. The thermal effect of HIPEC can enhance the cytotoxicity of chemotherapeutic agents [26-28]. However, combination of thermal effects and drug toxicity can lead to more side effects. The most common complications in the literature are anastomotic leakage, bone marrow suppression and wound infection. In our study, anastomotic or intestinal leakage occurred in 5 patients, 1 in control group and 4 in experimental group. Four patients showed grade II bone marrow suppression, 2 in each group. No would infection occurred in either group. There was no marked difference between the occurrence rates of postoperative complications. Prophylactic HIPEC with radical D2 gastrectomy was relatively safe for locally advanced gastric cancer.
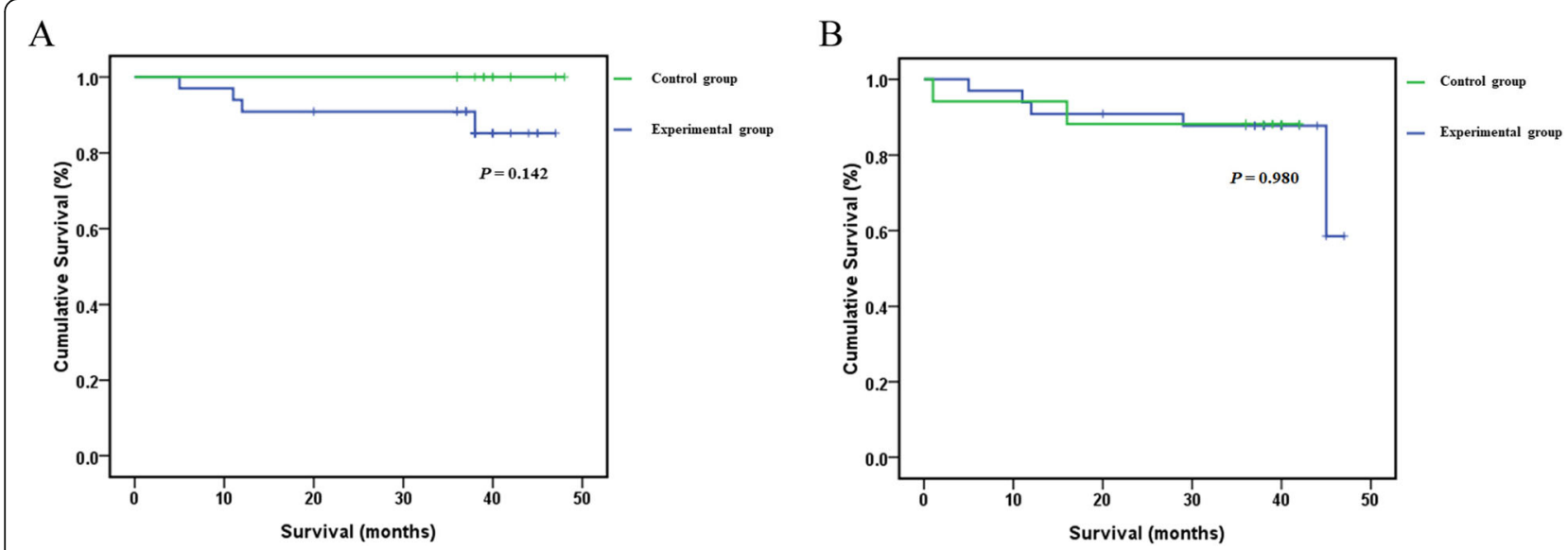

Fig. 1 Survival of patients with locally advanced gastric cancer after radical gastrectomy. a 3-year overall survival; b 3-year relapse-free survival 
A

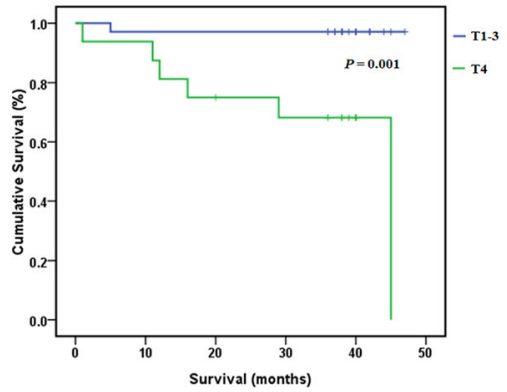

C

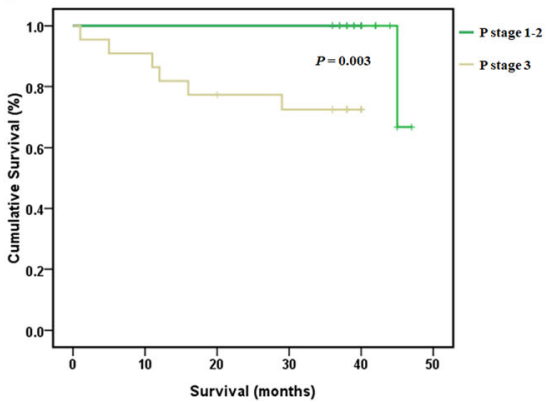

B

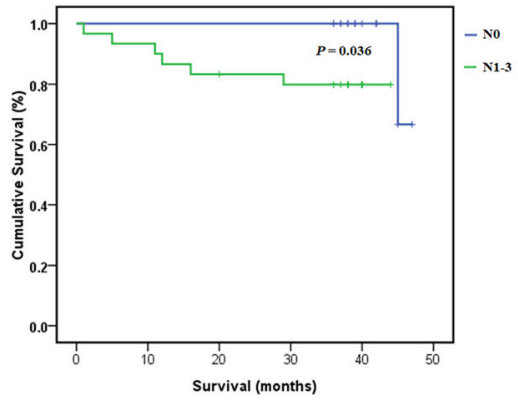

$\mathrm{D}$

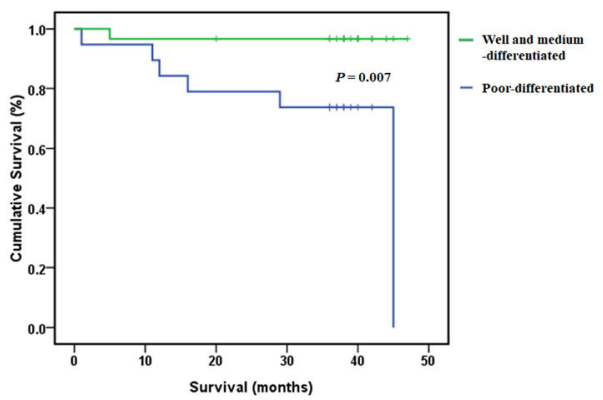

Fig. 2 Impact of tumor stage and tumor differentiation on patient relapse-free survival. a T stage; b N stage; c pTNM stage; $\mathbf{d}$ Tumor differentiation

Previous studies that investigated the role of HIPEC for preventing peritoneal recurrence in locally advanced gastric cancer have shown contradictory findings. Kang LY from Taiwan reported that radical gastrectomy with HIPEC had a better prognosis for locally advanced gastric cancer [29]. The 3-year DFS was $28.87 \%$ for patients who received surgery, while up to $66.03 \%$ for patients underwent surgery followed by HIPEC. The cancer recurrence was delayed in patients treated with HIPEC. In a recent study, Reutovich MY showed HIPEC with cisplatin and doxorubicin reduced metachronous peritoneal metastasis in radically operated serosa-invasive gastric cancer patients [30]. Another randomized study reported that prophylactic HIPEC with radical surgery improved survival and decreased incidence of peritoneal recurrence of advanced gastric cancer [18]. On the other hand, the PHOENIX-GC trial failed to show a survival benefit of intraperitoneal paclitaxel plus systemic chemotherapy in gastric cancer with peritoneal metastasis [31]. In the trial JCOG9206-2, adjuvant chemotherapy with intraperitoneal and intravenous cisplatin after radical gastrectomy did not improve patient overall and relapse free survival for patients with serosa-positive gastric cancer [32]. It should be noted that only $39 \%$ of patients who were treated with adjuvant chemotherapy actually completed the regime. Some patients have undergone radical gastrectomy with D2+ lymphadenectomy. For these two reasons, a possible effect of intraperitoneal chemotherapy as prophylaxis against peritoneal recurrence could not be excluded.

In the current trial, HIPEC did not improve the patient survival. In the multivariate survival analysis, only pathological $\mathrm{T}$ stage was significantly correlated with prognosis in locally advanced gastric cancer patients who underwent radical resection. HIPEC with cisplatin did not prolong patient survival in locally advanced gastric

Table 3 Multivariate predictors of survival

\begin{tabular}{|c|c|c|c|}
\hline Variables & Risk ratio & $95 \% \mathrm{Cl}$ & $P$ value \\
\hline Group, the experimental group /control & & & 0.925 \\
\hline T stage, $\mathrm{T} 1 \sim 3 / \mathrm{T} 4$ & 15.071 & $1.809-125.553$ & 0.012 \\
\hline Histological diagnosis, Well and intermediately differentiated/poorly differentiated & & & 0.360 \\
\hline Change of tumor markers, Decrease and stable/increase & & & 0.167 \\
\hline N stage, N0/N1-3 & & & 0.122 \\
\hline P stage, $1-2 / 3$ & & & 0.076 \\
\hline
\end{tabular}


cancer. Our results are not consistent with Reutovich MY's results though the research design of these two studies was similar [33]. Patients in HIPEC group of the two studies were both treated with curative resection followed by intraoperative HIPEC with cisplatin. However, there were more stage III patients enrolled in Reutovich MY's study and the patients were treated with HIPEC for a longer time $(60 \mathrm{~min})$ when compared with those in our study. A higher tumor stage indicates a higher probability of peritoneal recurrence and metastasis. The prolonged perfusion time could increase the antitumor efficacy of HIPEC. Taken together, these two studies imply that the perfusion time and selection of patients might affect the efficacy of HIPEC with cisplatin in the prevention of peritoneal recurrence. Interestingly, in our study, the percentage of patients with elevated tumor markers was significantly lower in the HIPEC group than in the control group. Since serum level of tumor markers can be used to monitor recurrence of cancer, these data suggest that HIPEC might inhibit the peritoneal recurrence.

This study has some limitations. In this randomized trial, only 50 patients were enrolled, the sample size may not be big enough to reach a statistically significant difference when comparing the HIPEC group with the control group (type-2 error). Secondly, this was a prospective controlled study. The inclusion criteria of locally advanced gastric cancer patients were based on clinical staging. CT scans were performed for the T staging. Studies have shown that the diagnostic accuracy of $\mathrm{CT}$ in determining $\mathrm{T}$ stage of gastric cancer was about 73.8-82.7\% [34, 35]. Due to the limitation of technology, in this study, 4 patients with T1 disease were overstaged as advanced gastric cancers. These patients were less likely to have peritoneal metastasis or cancer recurrence after radical surgery. This might have influenced the results of the study.

\section{Conclusion}

Prophylactic HIPEC with cisplatin was safe and well tolerated in patients with locally advanced gastric cancer. The survival benefit of HIPEC as a prophylactic therapy for locally advanced gastric cancer patients should be validated by prospective trials in a larger cohort.

\section{Abbreviations}

HIPEC: Hyperthermic intraperitoneal chemotherapy; RFS: Relapse free survival; BSA: Body surface area; Alb: Albumin; KPS: Karnofsky performance score; BMI: Body mass index; MSS/MSI: Micro-satellite stable/instable

\section{Acknowledgements}

We appreciate the hard work of the colleagues at the database center of our hospital who helped us reserve and search the relative data.

\section{Authors' contributions}

WXJ designed the study. The acquisition of data was conducted by FB, BZD, $Z J, Z X L, J X, F T$, JZY and ZYN. The data analysis and interpretation was performed by FB and WXJ. FB and WXJ drafted the manuscript. All authors have read and approved the manuscript.

\section{Funding}

This work is funded by the National Nature Science Foundation of China No. 81402308 and Science Foundation of Peking University Cancer Hospital No.2021-24 and No. A001546. The laboratory examination and treatment of patients were supported in part by the funders. The funders have had no role in any of the following; the design of the study and collection, analysis, and interpretation of data and in writing the manuscript.

\section{Availability of data and materials \\ The datasets used and analyzed during the current study available from the corresponding author on reasonable request.}

\section{Ethics approval and consent to participate}

This study was approved by the Ethics committee of Peking University Cancer Hospital. Written informed consent was obtained from all patients.

\section{Consent for publication}

Not Applicable.

\section{Competing interests}

All authors declare no conflict of interest.

Received: 7 October 2020 Accepted: 17 February 2021

Published online: 02 March 2021

\section{References}

1. Siegel RL, Miller KD, Jemal A. Cancer statistics, 2018. CA Cancer J Clin. 2018; 68(1):7-30.

2. Yang L, Zheng R, Wang N, Yuan Y, Liu S, Li H, Zhang S, Zeng H, Chen W. Incidence and mortality of stomach cancer in China, 2014. Chin J Cancer Res. 2018;30(3):291-8.

3. Sadeghi B, Arvieux C, Glehen O, Beaujard AC, Rivoire M, Baulieux J, Fontaumard E, Brachet A, Caillot JL, Faure JL, et al. Peritoneal carcinomatosis from non-gynecologic malignancies: results of the EVOCAPE 1 multicentric prospective study. Cancer. 2000;88(2):358-63.

4. Nashimoto A, Akazawa K, Isobe Y, Miyashiro I, Katai H, Kodera Y, Tsujitani S, Seto Y, Furukawa H, Oda I, et al. Gastric cancer treated in 2002 in Japan: 2009 annual report of the JGCA nationwide registry. Gastric Cancer. 2013; 16(1):1-27.

5. Thomassen I, van Gestel YR, van Ramshorst B, Luyer MD, Bosscha K, Nienhuijs SW, Lemmens VE, de Hingh IH. Peritoneal carcinomatosis of gastric origin: a population-based study on incidence, survival and risk factors. Int J Cancer. 2014;134(3):622-8.

6. Sugarbaker PH. New standard of care for appendiceal epithelial neoplasms and pseudomyxoma peritonei syndrome? Lancet Oncol. 2006;7(1):69-76.

7. Elias D, Lefevre JH, Chevalier J, Brouquet A, Marchal F, Classe JM, Ferron G, Guilloit JM, Meeus P, Goere D, et al. Complete cytoreductive surgery plus intraperitoneal chemohyperthermia with oxaliplatin for peritoneal carcinomatosis of colorectal origin. J Clin Oncol. 2009;27(5):681-5.

8. Bakrin N, Bereder JM, Decullier E, Classe JM, Msika S, Lorimier G, Abboud K, Meeus $P$, Ferron $G$, Quenet $F$, et al. Peritoneal carcinomatosis treated with cytoreductive surgery and Hyperthermic Intraperitoneal chemotherapy (HIPEC) for advanced ovarian carcinoma: a French multicentre retrospective cohort study of 566 patients. Eur J Surg Oncol. 2013;39(12):1435-43.

9. Ahmed S, Stewart JH, Shen P, Votanopoulos Kl, Levine EA. Outcomes with cytoreductive surgery and HIPEC for peritoneal metastasis. J Surg Oncol. 2014;110(5):575-84.

10. Xu DZ, Zhan YQ, Sun XW, Cao SM, Geng QR. Meta-analysis of intraperitoneal chemotherapy for gastric cancer. World I Gastroenterol. 2004;10(18):2727-30

11. Yan TD, Black D, Sugarbaker PH, Zhu J, Yonemura Y, Petrou G, Morris DL. A systematic review and meta-analysis of the randomized controlled trials on adjuvant intraperitoneal chemotherapy for resectable gastric cancer. Ann Surg Oncol. 2007;14(10):2702-13.

12. Yang XJ, Huang CQ, Suo T, Mei LI, Yang GL, Cheng FL, Zhou YF, Xiong B, Yonemura Y, Li Y. Cytoreductive surgery and hyperthermic intraperitoneal chemotherapy improves survival of patients with peritoneal carcinomatosis 
from gastric cancer: final results of a phase III randomized clinical trial. Ann Surg Oncol. 2011;18(6):1575-81.

13. Kim DW, Park DG, Song S, Jee YS. Cytoreductive surgery and Hyperthermic Intraperitoneal chemotherapy as treatment options for peritoneal metastasis of advanced gastric Cancer. J Gastric Cancer. 2018;18(3):296-304.

14. Fidler IJ. The pathogenesis of cancer metastasis: the 'seed and soil' hypothesis revisited. Nat Rev Cancer. 2003;3(6):453-8.

15. Glehen O, Mohamed F, Gilly FN. Peritoneal carcinomatosis from digestive tract cancer: new management by cytoreductive surgery and intraperitoneal chemohyperthermia. Lancet Oncol. 2004;5(4):219-28.

16. de Groot AE, Roy S, Brown JS, Pienta KJ, Amend SR. Revisiting seed and soil: examining the primary tumor and Cancer cell foraging in metastasis. Mol Cancer Res. 2017;15(4):361-70.

17. Bando E, Yonemura Y, Takeshita Y, Taniguchi K, Yasui T, Yoshimitsu Y, Fushida S, Fujimura T, Nishimura G, Miwa K. Intraoperative lavage for cytological examination in 1,297 patients with gastric carcinoma. Am J Surg. 1999;178(3):256-62.

18. Kuramoto M, Shimada S, Ikeshima S, Matsuo A, Yagi Y, Matsuda M, Yonemura Y, Baba H. Extensive intraoperative peritoneal lavage as a standard prophylactic strategy for peritoneal recurrence in patients with gastric carcinoma. Ann Surg. 2009;250(2):242-6.

19. Li Z, Li Z, Jia S, Bu Z, Zhang L, Wu X, Li S, Shan F, Ji X, Ji J. Depth of tumor invasion and tumor-occupied portions of stomach are predictive factors of intra-abdominal metastasis. Chin J Cancer Res. 2017;29(2):109-17.

20. Sarela Al, Lefkowitz R, Brennan MF, Karpeh MS. Selection of patients with gastric adenocarcinoma for laparoscopic staging. Am J Surg. 2006;191(1): 134-8.

21. Tsuchida K, Yoshikawa T, Tsuburaya A, Cho H, Kobayashi O. Indications for staging laparoscopy in clinical T4M0 gastric cancer. World J Surg. 2011; 35(12):2703-9.

22. Yoo CH, Noh SH, Shin DW, Choi SH, Min JS. Recurrence following curative resection for gastric carcinoma. Br J Surg. 2000;87(2):236-42.

23. Maehara Y, Hasuda S, Koga T, Tokunaga E, Kakeji Y, Sugimachi K. Postoperative outcome and sites of recurrence in patients following curative resection of gastric cancer. Br J Surg. 2000;87(3):353-7.

24. Seshadri RA, Glehen O. The role of Hyperthermic Intraperitoneal chemotherapy in gastric Cancer. Indian J Surg Oncol. 2016;7(2):198-207.

25. Coccolini F, Cotte E, Glehen O, Lotti M, Poiasina E, Catena F, Yonemura Y, Ansaloni L. Intraperitoneal chemotherapy in advanced gastric cancer. Metaanalysis of randomized trials. Eur J Surg Oncol. 2014;40(1):12-26.

26. Mohamed F, Marchettini P, Stuart OA, Urano M, Sugarbaker PH. Thermal enhancement of new chemotherapeutic agents at moderate hyperthermia. Ann Surg Oncol. 2003;10(4):463-8

27. Tang R, Zhu ZG, Qu Y, Li JF, Ji YB, Cai Q, Liu BY, Yan M, Yin HR, Lin YZ. The impact of hyperthermic chemotherapy on human gastric cancer cell lines: preliminary results. Oncol Rep. 2006;16(3):631-41.

28. Sugarbaker PH. Laboratory and clinical basis for hyperthermia as a component of intracavitary chemotherapy. Int J Hyperth. 2007;23(5):431-42.

29. Kang LY, Mok KT, Liu SI, Tsai CC, Wang BW, Chen IS, Chen YC, Chang BM, Chou NH. Intraoperative hyperthermic intraperitoneal chemotherapy as adjuvant chemotherapy for advanced gastric cancer patients with serosal invasion. J Chin Med Assoc. 2013;76(8):425-31.

30. Reutovich MY, Krasko OV, Sukonko OG. Hyperthermic intraperitoneal chemotherapy in serosa-invasive gastric cancer patients. Eur J Surg Oncol. 2019.

31. Ishigami H, Fujiwara Y, Fukushima R, Nashimoto A, Yabusaki H, Imano M, Imamoto H, Kodera Y, Uenosono Y, Amagai K, et al. Phase III trial comparing Intraperitoneal and intravenous paclitaxel plus S-1 versus Cisplatin plus S-1 in patients with gastric Cancer with peritoneal metastasis: PHOENIX-GC trial. J Clin Oncol. 2018;36(19):1922-9.

32. Miyashiro I, Furukawa H, Sasako M, Yamamoto S, Nashimoto A, Nakajima T, Kinoshita T, Kobayashi O, Arai K, Gastric Cancer surgical study Group in the Japan Clinical Oncology G. Randomized clinical trial of adjuvant chemotherapy with intraperitoneal and intravenous cisplatin followed by oral fluorouracil (UFT) in serosa-positive gastric cancer versus curative resection alone: final results of the Japan clinical oncology group trial JCOG9206-2. Gastric Cancer. 2011;14(3):212-8.

33. Beeharry MK, Zhu ZL, Liu WT, Yao XX, Yan M, Zhu ZG. Prophylactic HIPEC with radical D2 gastrectomy improves survival and peritoneal recurrence rates for locally advanced gastric cancer: personal experience from a randomized case control study. BMC Cancer. 2019;19(1):932.
34. Yan C, Zhu ZG, Yan M, Zhang H, Pan ZL, Chen J, Xiang M, Chen MM, Liu BY, Yin $\mathrm{HR}$, et al. Value of multidetector-row computed tomography in the preoperative T and N staging of gastric carcinoma: a large-scale Chinese study. J Surg Oncol. 2009;100(3):205-14.

35. Kim JW, Shin SS, Heo SH, Choi YD, Lim HS, Park YK, Park CH, Jeong YY, Kang HK. Diagnostic performance of 64-section CT using CT gastrography in preoperative T staging of gastric cancer according to 7 th edition of AJCC cancer staging manual. Eur Radiol. 2012;22(3):654-62.

\section{Publisher's Note}

Springer Nature remains neutral with regard to jurisdictional claims in published maps and institutional affiliations.
Ready to submit your research? Choose BMC and benefit from:

- fast, convenient online submission

- thorough peer review by experienced researchers in your field

- rapid publication on acceptance

- support for research data, including large and complex data types

- gold Open Access which fosters wider collaboration and increased citations

- maximum visibility for your research: over $100 \mathrm{M}$ website views per year

At BMC, research is always in progress.

Learn more biomedcentral.com/submissions 